REFERENCIA: del Río-Fernández, J. L. (2021). La secuencia didáctica de escritura como estrategia pedagógica para la mejora progresiva de la redacción y el fomento de la cohesión grupal. ENSAYOS, Revista de la Facultad de Educación de Albacete, 36(2), 47-59. Enlace web: http://www.revista.uclm.es/index.php/ensayos - Consultada en fecha (dd-mm-aaaa)

\title{
LA SECUENCIA DIDÁCTICA DE ESCRITURA COMO ESTRATEGIA PEDAGÓGICA PARA LA MEJORA PROGRESIVA DE LA REDACCIÓN Y EL FOMENTO DE LA COHESIÓN GRUPAL
}

\section{THE DIDACTIC SEQUENCE OF WRITING AS A PEDAGOGICAL STRATEGY FOR THE PROGRESSIVE IMPROVEMENT OF WRITING AND THE PROMOTION OF GROUP COHESION}

\author{
José Luis del Río-Fernández \\ joseluisdelrio@uma.es \\ Universidad de Málaga
}

Recibido: $11 / 08 / 2021$

Aceptado: 23/11/2021

\begin{abstract}
Resumen:
En el artículo se describe una experiencia de aprendizaje llevada a cabo en la Universidad Nacional de Educación (UNAE) consistente en aplicar la secuencia didáctica de escritura en el marco de la asignatura Lectura y Escritura de Textos Académicos I con un doble propósito: por un lado, procurar la mejora progresiva de las competencias básicas del alumnado en el campo de la comunicación escrita; y, por otro, intentar fomentar la cohesión grupal gracias al análisis de unos autorretratos anónimos que sirvieron como pretexto para ejecutar los correspondientes ejercicios de redacción. El trabajo se desarrolla desde los parámetros de la investigación-acción y tiene un enfoque narrativo-interpretativo. Los resultados obtenidos ponen de manifiesto la importancia de atender las relaciones personales en cualquier contexto educativo -incluido el universitario-y plantea la necesidad de proponer actividades académicas dirigidas no solo a la adquisición de conocimientos teóricos, sino también a la formación integral y humana.
\end{abstract}

Palabras clave: secuencia didáctica de escritura; comunicación escrita; cohesión grupal; competencia comunicativa; investigación-acción; formación integral.

\begin{abstract}
:
The article presents a learning experience developed at National University of Education (UNAE) consisting of applying the didactic sequence of writing in the subject Reading and Writing of Academic Texts I with a dual purpose: first of all, seek the progressive improvement of basic skills in the field of written communication; on the other side, try to promote group cohesion thanks to the analysis of some anonymous self-portraits that served as a pretext to make the corresponding writing exercises. The work is developed from the parameters of action-research and has a narrative-interpretive approach. The results obtained reveal the importance of attending to personal relationships in any educational context -including the university - and raises the need to propose academic activities aimed not only at the acquisition of theoretical knowledge, but also at the human and comprehensive training of students.
\end{abstract}

Keywords: didactic sequence of writing; written communication; group cohesion; communicative competence; action-research; integral formation. 


\section{Introducción}

Aunque pueda parecer una afirmación obvia, el único modo que tenemos los seres humanos de aprender a escribir es escribiendo (Díez-Coronado, 2016). No hay otro camino. Nadie puede adquirir y desarrollar la capacidad de seleccionar las palabras adecuadas para que logren expresar aquello que nos pasa por la cabeza y por el corazón viendo cómo escriben los demás y adoptando una actitud pasiva ante ello. Es necesario enfrentarse en primera persona al papel en blanco, superar los miedos iniciales, probar y equivocarse, avanzar y retroceder. En definitiva, ponerse manos a la obra y tratar de ir ganando experiencia a medida que vamos redactando textos, acumulando errores y aprendiendo de ellos. En este sentido, no hay que olvidar que escribir es un verbo activo, y como todos los verbos activos, es necesario conjugarlo en gerundio para que alcance su plenitud. Ahora bien, no estamos hablando de una tarea que resulte sencilla. Escribir - sobre todo, escribir correctamente - requiere, por un lado, de tiempo, paciencia y constancia; y por otro, de acompañamiento (Cassany, 1995). Como docentes universitarios, ese debería ser uno de nuestros principales cometidos: asesorar al alumnado en este proceso de aprendizaje, señalar sus desatinos, alabar sus aciertos, confiar en sus posibilidades y proponerles retos que contribuyan a la mejora paulatina de sus competencias comunicativas (Boillos-Pereira, 2018; Tobón Tobón, Pimienta Prieto y García Fraile, 2010).

Gómez-Pardo (2012) dice que el análisis de los métodos a través de los cuales se enseña a leer y a escribir en la universidad entraña una reflexión sobre el uso que se le da a la escritura en los contextos académicos, a la vez que abre un debate sobre si priman más los postulados instructivos o constructivos a la hora de acometer esta tarea. Lo cierto es que ambos enfoques pueden llegar a complementarse perfectamente, siempre y cuando la intencionalidad del profesorado sea que sus estudiantes adquieran un aprendizaje que resulte útil, valioso y significativo.

Partiendo de esta premisa fundamental, a lo largo de las siguientes páginas se describe una singular actividad llevada a cabo por el autor del presente texto durante el curso académico 2019/2020, mientras desempeñaba su labor docente en la Universidad Nacional de Educación (UNAE).

Esta institución pública de educación superior, que comienza su andadura en mayo del año 2015, está ubicada en Javier Loyola - también conocida como Chuquipata - una pequeña parroquia perteneciente a Azogues, capital de la provincia del Cañar (Ecuador). Actualmente, cuenta con más de cinco mil estudiantes en las modalidades presencial y a distancia, y ofrece las siguientes carreras: Educación Básica, Educación Inicial, Educación Intercultural Bilingüe, Educación Especial, Educación en Ciencias Experimentales, Pedagogía de las Artes y Humanidades, y Pedagogía de los Idiomas Nacionales y Extranjeros.

La experiencia de aprendizaje que se constituye como objeto de estudio se realizó en el marco de la asignatura Lectura y Escritura de Textos Académicos I, una materia obligatoria de 18 horas presenciales que se imparte en el sexto ciclo de la carrera de Educación Inicial y cuya distribución se hace a razón de una sesión semanal de 60 minutos de duración, más el correspondiente tiempo dedicado al seguimiento y a la tutorización del alumnado a través del aula virtual alojada en la plataforma moodle de la universidad.

Atendiendo a las disposiciones establecidas en la guía docente, el objetivo general que se espera alcanzar con esta asignatura es el perfeccionamiento de la expresión escrita del alumnado. Para intentar alcanzarlo, se optó por aplicar en el aula una estrategia metodológica conocida como secuencia didáctica de escritura (Dolz y Schneuwly, 2011; Tobón Tobón et al., 2010), cuya efectividad, independientemente del nivel educativo en el que se implemente, ya ha sido puesta 
de manifiesto en estudios previos (Di Stefano, Pereira y Pipkin, 2006; España Palop, 2012; Hocevar, 2007; Martínez y Astudillo, 2021; Monsalve Flórez, 2021; Moreno Serna, Galindo y Murillo, 2021; Santolària Òrrios, 2019; Tapia-Ladino, Correa, Ortiz y Neira, 2012). Sin embargo, dada la excepcional circunstancia de que el grupo lo componían únicamente 12 estudiantes todas pertenecientes al sexo femenino- se presentaban las condiciones idóneas para, de manera transversal, procurar también cuidar las relaciones humanas y contribuir a la cohesión grupal, entendiendo que una ratio tan reducida de alumnado por aula supone una gran ventaja para proponer tareas en las que se fomente el trabajo en equipo y el reconocimiento de aquellas personas con las que se tiene la suerte de compartir tiempos, espacios y experiencias de aprendizaje (Del Río-Fernández, 2019).

\subsection{La secuencia didáctica de escritura como estrategia para la mejora progresiva de la expresión escrita}

La secuencia didáctica de escritura es una estrategia para el desarrollo de la expresión escrita que se sustenta en un proceso gradual de elaboración y reelaboración de textos. Según Dolz y Schneuwly (2011, p. 3), "el reto de las secuencias didácticas es conseguir hacer de ese primer texto inicial un medio y un soporte para precisar el pensamiento, para afinar la imaginación y para desarrollar la claridad de la expresión". El propósito de esta metodología es hacer ver al alumnado que un buen escrito no brota de la noche a la mañana ni es fruto del azar, sino que es el resultado de una revisión consciente y sistemática del borrador preliminar. En otras palabras, que la escritura conlleva reescritura, transformación y perfeccionamiento (Cassany, 1995).

Siguiendo a España Palop (2012), su aplicación en el salón de clases da respuesta a dos aspectos que resultan de vital importancia: por un lado, permite trabajar la escritura a partir de géneros concretos y de forma contextualizada; por otro, posibilita centrar la atención del profesorado en las necesidades formativas de quienes aspiran a mejorar su competencia lingüística. Esta estrategia conlleva, además, que los estudiantes disfruten del acto de escribir, ya que no suele ser frecuente que se les solicite la creación de textos originales que tengan intención comunicativa (Ruiz Flores, 2009; Tapia-Ladino et al., 2012). Por lo general, siguiendo la tradición académica más ortodoxa, cuando se les ha pedido a los discentes que escriban, ha sido para que repitan y asimilen las ideas que otras personas han elaborado previamente, no para que creen ideas nuevas y trabajen a partir de ellas, asumiendo el papel de escritores transmisionales en lugar de escritores transaccionales (Errázuriz-Cruz, 2020). Sin embargo, de acuerdo con Martínez y Astudillo (2021, p. 10), "la escritura en la universidad debería abordarse como una herramienta de apropiación-construcción y divulgación del conocimiento, debido a que la permanencia en el tiempo del signo lingüístico permite la abstracción y reflexión sobre dicho acto comunicativo". Desde esta perspectiva, se defiende la implementación de la secuencia didáctica de escritura en los procesos formativos.

Según Di Stefano et al. (2006), para que la secuencia alcance todo su potencial educativo se deben contemplar varios momentos: la preparación o introducción al tema, la explicitación de los objetivos que se pretenden alcanzar, el desarrollo de las actividades y la evaluación. En cada una de ellas, el profesorado debe hacer las veces de guía y ofrecer retroalimentación, con el consecuente esfuerzo que ello conlleva. En tal sentido, la puesta en marcha de esta metodología no está exenta de dificultades y las propias autoras señalan algunas: "la búsqueda de recursos, la claridad conceptual, la determinación y jerarquización de los objetivos y contenidos, la secuenciación de actividades en función del nivel educativo y del momento de aplicación, etc." (Di Stefano et al., 2006, p. 127). Sin embargo, a pesar de todos los obstáculos que haya que superar, se considera que son más las ventajas que los inconvenientes. La secuencia didáctica de escritura convierte al alumnado en protagonista del aprendizaje, favorece el trabajo autónomo, fomenta la colaboración entre estudiantes, induce el pensamiento divergente, 
estimula la creatividad y contribuye al análisis crítico del uso de la lengua (Tobón Tobón et al., 2010).

Además, desde una óptica pedagógica, la composición de textos mediante la secuencia didáctica de escritura aparece como una valiosa oportunidad para que el profesorado aplique la evaluación formativa en el contexto universitario (Hidalgo Apunte, 2021). Al focalizar la atención en la identificación de los errores cometidos y en el análisis de las posibles alternativas de mejora, el carácter punitivo desaparece del proceso. Dicho de otro modo, si la meta última de esta acción educativa es el desarrollo gradual de la expresión escrita - algo que no puede medirse en términos absolutos porque siempre existirá un margen de medra - resulta evidente que el producto final no ha de tener tanta relevancia como el aprendizaje que emerja fruto de la experiencia. ¿O es que acaso es posible alcanzar el máximo grado de desarrollo en una capacidad tan compleja y susceptible de constante perfeccionamiento como es la redacción? (Dolz y Schneuwly, 2011).

\subsection{La importancia de aprender a describir y a interpretar}

Uno de los objetivos específicos declarados de la asignatura Lectura y Escritura de Textos Académicos I es "que el alumnado aprenda a describir y a interpretar utilizando diferentes estilos de redacción, con la finalidad de que puedan aplicar ambos procesos en la elaboración de los diarios de campo" (así aparece establecido literalmente en la guía docente) y para contextualizar esta frase quizá sea necesario hacer un inciso: los estudiantes de la Universidad Nacional de Educación (UNAE) desarrollan un periodo de práctica preprofesional en cada uno de los ciclos que componen la carrera y deben asistir a los centros educativos que se les asignen durante un tiempo determinado. ${ }^{1}$ Para sistematizar la experiencia formativa, el profesorado universitario responsable de su tutorización suele solicitar la elaboración de un diario de campo en el que queden registradas las distintas evidencias y que se constituya, a su vez, como una herramienta de aprendizaje. La pretensión de esta exigencia es ir sentando las bases para que, en un futuro, cuando ingresen al mundo laboral, se conviertan en docentes-investigadores con plena capacidad para analizar su propia actividad profesional (Del Río-Fernández, 2019). En esta línea de pensamiento, Boillos-Pereira (2018, p. 18) afirma:

A diferencia de lo que el estudiante espera, escribir en el ámbito académico no consiste únicamente en poner en práctica las habilidades, estrategias y recursos que ha ido progresivamente adquiriendo en las etapas educativas anteriores. Por el contrario, escribir en la universidad exige, también, dominar esta competencia como para poder llevar a cabo prácticas sociales situadas y que dependen del ámbito disciplinar en el que se están produciendo.

Por este motivo, es necesario que el estudiantado de Educación Inicial aprenda a describir situaciones y a interpretarlas de manera adecuada, utilizando la escritura como medio de expresión, ya que este ejercicio contribuye al desarrollo de la reflexión y el pensamiento crítico (Del Río-Fernández, 2019). Ahora bien, cabe señalar que la descripción y la interpretación/argumentación son procesos comunicativos distintos (Casas i Vilalta, Bosch y González Monfort, 2005; Murillo Sandoval y Martínez Valencia, 2014; Rojas Tapia, 2014). El primero alude a los hechos -es más objetivo- y el segundo, a los juicios - es más subjetivomientras que la descripción busca la enumeración de las cualidades, características o propiedades de un objeto, fenómeno o realidad social, la interpretación/argumentación alude

\footnotetext{
${ }^{1}$ En las carreras de educación de las universidades españolas, estos periodos se corresponderían con los llamados "Prácticum".
} 
al campo de los valores y consiste en exponer de forma ordenada una serie de ideas y/o razonamientos que justifiquen un posicionamiento personal (Casas et al., 2005).

Tomando como referencia la trayectoria docente recorrida en los ciclos previos, lo cierto es que la mayoría de las alumnas (y también de los pocos alumnos que cursan esta carrera) muestran dificultades significativas para distinguir entre un proceso y otro. De hecho, es habitual que, cuando se les pide que analicen una realidad o un fenómeno determinado aplicando la descripción y la interpretación en sus redacciones, los escritos resultantes sean confusos y poco claros. Por consiguiente, la diferenciación entre estilos narrativos y la mejora de la expresión escrita en estos dos ámbitos se constituye como una prioridad inexcusable y como un desafío para el profesorado universitario (Boillos-Pereira, 2018; Martínez y Astudillo, 2020).

Ahora bien, como ya se ha señalado anteriormente, la duración total de esta materia es de solo 18 horas. Queda patente que el tiempo disponible para el trabajo en el aula no es mucho y que las expectativas de progreso deben estar consonancia con las condiciones existentes. Así pues, resultó necesario desde un principio seleccionar muy bien las tareas que se iba a presentar al alumnado en aras de intentar sacar el máximo provecho posible a cada una de las sesiones.

\section{Método}

Con la finalidad de describir la potencialidad educativa que encierra la secuencia didáctica de escritura para el perfeccionamiento de la expresión escrita y también como estrategia metodológica para el fomento de la cohesión grupal, se presenta un trabajo de corte cualitativo diseñado bajo los parámetros de la investigación-acción (Elliott, 2009; McKernan, 1999) y desarrollado desde un enfoque narrativo-interpretativo (Flores y Porta, 2021; Molina et al., 2020). La pretensión no es generalizar los resultados obtenidos, ya que no se cuenta con una muestra poblacional lo suficientemente representativa, sino describir con cierta profundidad las acciones concretas desarrolladas en un contexto educativo particular para procurar su comprensión.

Las personas participantes en el estudio fueron las 12 estudiantes que componían el grupo de clase correspondiente al sexto ciclo de Educación Inicial, así como el profesor responsable de la asignatura Lectura y Escritura de Textos Académicos I, que ejercía de manera simultánea la labor docente e investigadora.

Las técnicas para la recogida de información fueron la observación participante -se realizaron un total de 18 observaciones, una por cada sesión de clase-, la elaboración semanal de un diario de campo, el registro de evidencias mediante la toma de fotografías y el análisis de las producciones elaboradas a lo largo de la asignatura. Adicionalmente, al finalizar el periodo lectivo, se solicitó a las alumnas la cumplimentación de un cuestionario que constaba de dos partes: la primera estaba compuesta por cinco preguntas de respuesta abierta; y la segunda, por cinco ítems que contenían una escala de valoración tipo Likert de uno a cuatro puntos (donde uno era muy en desacuerdo y cuatro completamente de acuerdo), con el fin de conocer el nivel de satisfacción con la docencia recibida. ${ }^{2}$ Gracias a este instrumento, fue posible contrastar las impresiones recabadas por el profesor a lo largo del proceso formativo.

En los apartados siguientes se detallará cuál fue la dinámica de trabajo seguida durante el desarrollo de la asignatura.

\footnotetext{
${ }^{2}$ Algunas de las respuestas aparecerán transcritas de manera literal en páginas posteriores. El anonimato de las informantes se respetará mediante el uso de la clave (A.X), donde A significa "alumna" y X el número asignado a cada una de ellas.
} 


\subsection{Punto de partida: haz un retrato de ti en el que no salgas tú}

Antes de dar inicio a la secuencia didáctica de escritura es necesario escribir sobre algo y que la producción resultante se convierta en la materia prima con la que empezar a trabajar en el aula (Tobón Tobón et al., 2010). Ese algo bien puede ser una redacción sobre las vacaciones ideales, un comentario de texto, una reseña sobre la última película que se haya visto en el cine o un resumen que contenga las ideas fundamentales de una lectura realizada previamente. Las posibilidades son infinitas. En el caso que nos ocupa, la intención era que las estudiantes escribieran sobre algo que les resultara estimulante, llamativo y fuera de lo convencional. Finalmente, se les instó a que describieran e interpretaran una imagen. Pero no una imagen cualquiera, sino unos autorretratos anónimos elaborados por sus propias compañeras. Ese sería el punto de partida para poner en marcha la estrategia metodológica.

Así pues, se les pidió a las alumnas que, en casa, hicieran un retrato de ellas en el que no salieran ellas y procedieran a remitirlo sin firmar a través de una pestaña habilitada en el aula virtual. Haz un retrato de ti en el que no salgas tú fue la única instrucción que recibieron, y si bien se tomó como referencia la definición de retrato propuesta por la Real Academia de la Lengua Española en su acepción más amplia (descripción de las cualidades físicas o morales de una persona), lo cierto es que la interpretación de dicho concepto es libre, por lo que el formato de elaboración del trabajo también lo era. Las estudiantes podían elegir entre dibujo, pintura, escultura, fotografía, etc., y usar el material que estimasen oportuno. La intención implícita de esta invitación era animarlas a dejar a un lado la práctica del selfie - un ejemplo paradigmático del egocentrismo que caracteriza la sociedad actual- y plantearles que intentaran retratarse de una manera distinta, en la cual, la representación del "yo" no se limitase a la simple exaltación de las cualidades apreciables a simple vista.

Una vez recibidos todos los retratos, se imprimieron en hojas de papel DIN A4, fueron llevados a clase y repartidos aleatoriamente, procurando que a nadie le tocara el suyo. Seguidamente, se les pidió que dieran forma a un escrito cuya extensión oscilara entre las 2000-2500 palabras y que constara de dos partes. En la primera, debían incluir una descripción lo más aséptica y objetiva posible de la imagen asignada, señalando los diferentes elementos que la componían: objetos que aparecen, disposición espacial, formas, colores, tamaños, etc., teniendo en cuenta que:

El problema más importante para elaborar un texto descriptivo suele ser la dificultad para encontrar características y cualidades de los hechos o fenómenos sociales observados, saberlas jerarquizar y saber utilizar los conectores correctamente. Cuanto más rica y amplia sea la descripción, más completa, rigurosa y precisa será la posterior explicación y la justificación. (Casas et al., 2005, p. 44)

En la segunda parte del texto se debía realizar una interpretación de la imagen previamente descrita, detallando los motivos específicos por los que la asociarían con alguna compañera del grupo y procurando justificar adecuadamente los argumentos esgrimidos, ya fuesen reales o hipotéticos. Para ello, resultaba imprescindible preguntarse qué sabemos, o qué creemos saber, de las personas con las que se compartía el aula, ya que la mayoría de las imágenes se prestaban a múltiples lecturas. No obstante, es necesario subrayar que, por el momento, el objetivo no era adivinar a quién pertenecía el retrato y acertar en las elucubraciones, sino tan solo describir e interpretar la imagen adjudicada procurando redactar de la mejor manera posible.

\subsection{Descripción de las fases que componían la secuencia didáctica de escritura}

Con ese texto primario encima de la mesa, se inició el proceso de perfeccionamiento progresivo del escrito, asumiendo que "trabajar sobre un texto ya existente contribuye a descubrir y 
aprender que dicho texto puede ser un punto de partida que se puede mejorar" (Dolz y Schneuwly, 2011, p. 4). Para ello, se siguieron las recomendaciones de Hocevar (2007), quien nos advierte que leer y corregir los textos de otra persona resulta, a veces, más fácil que detectar los fallos cometidos por uno mismo. A tal efecto, se decidió dividir el grupo clase en subgrupos de tres alumnas. Cada una de ellas debía someter el escrito que le fuese asignado a las fases que pasaremos a explicar a continuación y, posteriormente, ceder el texto a la compañera que estuviese sentada a su derecha, para que esta, a su vez, también procediera a su revisión y mejora.

Una vez aclaradas las indicaciones básicas, la secuencia didáctica de escritura se llevó a cabo atendiendo a las fases siguientes:

- Fase 1. Revisión gramatical y corrección de la ortografía: el primer momento consistió en comprobar el uso correcto de tildes, signos de puntuación, concordancias, reiteraciones, adecuación de tiempos verbales, etc., identificando los errores y señalándolos con un subrayador de color. Para facilitar la tarea, se proporcionó al alumnado un material básico de apoyo seleccionado exprofeso al que podían acceder fácilmente desde el aula virtual. La justificación para comenzar con este ejercicio radicó en las enormes carencias léxico-gramaticales y semántico-discursivas con las que, por lo general, la juventud ecuatoriana suele ingresar a la universidad (Montesdeoca-Arteaga, Palacios-Briones, Gómez-Parra y Espejo-Mohedano, 2021). Una realidad que también existe en otros países de habla hispana -incluida España- y que se constituye como todo un reto para el profesorado (Boillos-Pereira, 2018; Gutiérrez-Rodríguez y FloresRomero, 2011).

- Fase 2. Análisis de la coherencia interna del texto y uso de conectores parentéticos e integrados: en esta segunda fase, cada compañera tenía la opción de replantear el texto correspondiente aplicando los contenidos vistos en las sesiones teóricas de la asignatura. Por ejemplo, la organización de la información siguiendo la estructura tipo -introducción, desarrollo y conclusiones - o la utilización de los conectores aditivos, contraargumentativos, causales/consecutivos, reformuladores o discursivos (Teberosky, 2007), con el fin de dotar de orden, coherencia y lógica interna al escrito.

- Fase 3. Adecuación de los estilos de redacción utilizados para describir e interpretar. Tomando como referencia la diferenciación entre prototipos textuales (Rojas Tapia, 2014) y las recomendaciones de estilo a la hora de describir y de interpretar (Murillo Sandoval y Martínez Valencia, 2014), cada estudiante debía reescribir el texto correspondiente reformulando, añadiendo, suprimiendo y/o parafraseando ideas. El objetivo de este tercer paso era enriquecer y completar el texto inicial con nuevas apreciaciones.

Tobón Tobón et al. (2010) afirman que una secuencia didáctica se puede hacer para toda la asignatura o para cada uno de los módulos que la conforman. Eso sí, "se sugiere que no se elabore para una única clase, sino que articule al menos dos sesiones de aprendizaje" (2010, p. 60). En el caso que nos ocupa, el desarrollo de la secuencia didáctica abarcó 10 de las 18 sesiones de las que constaba la asignatura. El trabajo en el aula se alternaba con la presentación de contenidos teóricos, dedicando una media de 30 minutos para cada actividad. De esta manera, las alumnas podían revisar y mejorar los textos asignados aplicando dichos contenidos. "En el enfoque socioformativo, los bloques o temas se convierten en ejes procesuales; con ello pasan de ser contenidos a elementos dinamizadores de la formación y ayudan a organizar las secuencias didácticas para dosificar mejor el aprendizaje de los estudiantes" (Tobón Tobón et al., 2010, p. 64). 
Una vez que todos los escritos pasaron por las tres frases señaladas (revisión gramatical y corrección de la ortografía, análisis de la coherencia interna y adecuación de los estilos de redacción), fueron devueltos a las autoras de las descripciones e interpretaciones originales, quienes debían revisar las aportaciones hechas por las compañeras, valorar su pertinencia y reelaborar de nuevo el texto para entregar a través del aula virtual la versión definitiva del mismo.

En sesiones posteriores se procedió a la evaluación y a la calificación de estas producciones finales. Cada uno de los textos enviados fue escaneado, compartido en la pantalla del aula y leído en voz alta por el docente, quien se encargó de sugerir pequeñas modificaciones o de señalar aquellos errores que las estudiantes habían pasado por alto en las correcciones previas. Con ello, se puso de manifiesto que la perfección no existe y que siempre es posible optimizar un escrito, a pesar de las múltiples revisiones hechas. No obstante, las propias alumnas pudieron corroborar que las diferencias existentes entre los primeros textos y las versiones finales eran evidentes.

\subsection{Aprender a convivir mientras se aprende a escribir. La actividad formativa como pretexto para el fomento de la cohesión grupal}

La experiencia de aprendizaje se cerró proyectando en la pizarra interactiva cada uno de los retratos anónimos de las estudiantes junto a los textos definitivos que contenían las descripciones e interpretaciones elaboradas por sus compañeras, para comprobar si las imágenes correspondían o no a las personas a las que habían sido asociadas en un principio. Por supuesto, hubo casos en los que las estudiantes ya habían adivinado previamente y sin vacilación a quién pertenecían determinados retratos antes incluso de ponerse a escribir, ya que reconocieron en ellos detalles que identificaron rápidamente con alguna compañera en particular. Sin embargo, en otros casos no sucedió así, debido a que también hubo retratos más introspectivos que contenían un trasfondo muy valioso para conocer los universos particulares de sus autoras y que, evidentemente, requirieron de mayor esfuerzo a la hora de intentar adivinar a quién correspondían.

En definitiva, la puesta en común de las producciones resultantes tras la aplicación de la secuencia didáctica de escritura permitió no solo comparar los textos iniciales con los finales y apreciar las mejoras hechas, sino también introducir un debate en clase sobre las características identitarias susceptibles de reconocimiento en cada compañera, sobre la necesidad que tenemos los seres humanos de aprender a convivir con quienes son diferentes y sobre la importancia de desmontar los prejuicios que, desafortunadamente, tendemos a construir de manera errónea tomando como referencia impresiones vagas y personales que, por lo general, no se suelen corresponder con la realidad. Como bien señaló una de las alumnas, “¿cuántas veces, a lo largo de nuestra vida, habremos cometido el error de juzgar a las personas sin haberlas conocido antes, dejándonos llevar únicamente por la impresión que nos dan, los rumores que nos llegan o aspectos tan triviales como la indumentaria o el tipo de peinado?" (A.2).

\section{Resultados}

Los resultados obtenidos tras la puesta en práctica de esta estrategia metodológica no pueden medirse de manera cuantitativa, trasladando a fríos números y/o a porcentajes todo el trabajo desarrollado a lo largo de las diferentes sesiones. Además, aunque la estadística reflejara un $100 \%$ de éxito, sería una muestra de ingenuidad afirmar que la capacidad de redacción de todas las componentes del grupo alcanzó la excelencia tras la puesta en práctica de la actividad, ya que las horas de clase fueron escasas y los contenidos teóricos abordados muy reducidos para 
dar respuesta al ambicioso objetivo general de la asignatura ("el perfeccionamiento de la expresión escrita del alumnado"). Sin embargo, es de justicia reconocer que sí hubo avances significativos.

Las estudiantes fueron capaces de detectar los errores de redacción más frecuentes (confusión en las palabras homófonas, ausencia de tildes diacríticas en los pronombres interrogativos, uso inadecuado de los signos de puntuación, frases o expresiones mal construidas, discordancias gramaticales, etc.) y proceder a su corrección. Además, dieron forma a unos textos bien secuenciados mediante el uso de conectores tales como: en primer lugar, seguidamente, por otra parte, en suma, etc. Asimismo, lograron aplicar diferentes estilos narrativos para distinguir la descripción de la interpretación, utilizando el lenguaje impersonal para la realización de las descripciones (se observa, se aprecia, podemos destacar, etc.), y el uso de una redacción más subjetiva para expresar opiniones o pensamientos (desde mi punto de vista, a tenor de la experiencia, a mi parecer, etc.). Por consiguiente, aunque no se llegó a la perfección de los textos, sí que se logró el perfeccionamiento progresivo, haciendo hincapié en que el propósito de la experiencia nunca fue que el producto final tuviese más valor que el proceso.

Con esta dinámica tendente a la metacognición, las estudiantes pudieron ser conscientes de que la escritura en contextos académicos "no solo se limita a informar, sino que es también una herramienta epistémica que promueve el aprendizaje y sirve para transformar el conocimiento e, incluso, para crearlo" (Errázuriz-Cruz, 2020, p. 12). En este sentido, una alumna reconoció que en esta asignatura "había aprendido más sobre el poder y el valor que tienen las palabras que en todo lo que llevaba de carrera" (A.1).

Por otra parte, se considera que la experiencia contribuyó a fomentar la creatividad, una competencia que no puede aprenderse a golpe de dictado, sino que se va adquiriendo e interiorizando de forma paulatina, siempre y cuando los retos propuestos inviten a utilizar el pensamiento divergente (Robinson, 2009). En el caso que nos ocupa, la capacidad creativa de las estudiantes no solo se vio plasmada en la exigencia de elaborar unos retratos de ellas en los que no salieran ellas - y que precisaban, por tanto, del uso de elementos figurados, simbólicos, alegóricos o metafóricos en sus producciones-, sino también en la construcción de los textos descriptivos e interpretativos que cada alumna hizo de las imágenes asignadas. Cabe señalar la gran variedad de recursos imaginativos utilizados para desentrañar los posibles significados que encerraban los retratos ajenos.

Una vez finalizadas las clases, también es posible afirmar que se cumplió con otro de los propósitos establecidos desde un inicio: fomentar la cohesión grupal. Algo que, lamentablemente, tampoco se puede medir con la supuesta precisión y objetividad que dan las cifras, de modo que hay que dejarse llevar por las intuiciones, las impresiones y los momentos puntuales captados mediante las observaciones y las fotografías realizadas a lo largo de las sesiones de clase. En cualquier caso, es indudable que la aplicación de la secuencia didáctica de forma colectiva se constituyó como una posibilidad para aprender de las compañeras y con las compañeras, fomentando el sentimiento de pertenencia a un grupo y abogando por la cooperación en detrimento de la competitividad. A su vez, el hecho de trabajar la escritura a partir de la identificación de los retratos anónimos fue la excusa perfecta para recordar que las personas somos mucho más de lo que mostramos a simple vista, de modo que es necesario hacer un esfuerzo por conocer mejor a quienes tenemos a nuestro lado. Porque, ¿qué sentido tiene formarse en una universidad de educación si su paso por ella no sirve para desarrollar la dimensión humana y aprender a valorar a nuestros semejantes? ¿Para qué sirve enseñar a escribir con absoluta corrección si las ideas que transmitimos con nuestras acciones en el aula son contrarias a principios tales como la empatía, la generosidad, la cooperación o el compañerismo? 
En la valoración final de la docencia recibida, consistente en un cuestionario compuesto por cinco preguntas de respuesta abierta y cinco ítems que contenían una serie de afirmaciones valorables en una escala Likert de uno a cuatro puntos, las estudiantes afirmaron haber disfrutado del ejercicio de retroalimentación y evaluación por pares, lo que corrobora la defensa de la tutoría entre iguales para abordar desde un enfoque pedagógico los procesos de enseñanza de escritura académica (Chois-Lenis, Casas-Bustillo, López-Higuera, Prado-Mosquera y Cajas-Paz, 2017; Monsalve Flórez, 2021). A su vez, el 100\% del alumnado se mostró completamente de acuerdo ante el ítem "creo que esta asignatura ha contribuido a la mejora de la cohesión grupal", reconociendo que, gracias a la actividad de revisión conjunta de los escritos, tuvieron la oportunidad de interactuar con compañeras con las que nunca antes habían trabajado y de establecer vínculos afectivos entre ellas. Algunas de las declaraciones de las alumnas fueron las siguientes:

- "En esta asignatura no se compite para ver quién saca la mejor nota, para comprobar quién escribe mejor o quién escribe peor. Todas aprendemos de todas y los textos individuales se mejoran gracias a la colaboración" (A.3).

- "Me sentía muy a gusto trabajando con las compañeras del grupo, a pesar de que nunca había compartido mesa con ellas" (A.6).

- "Ha habido un buen ambiente de clase desde el primer día" (A.8).

- "Aunque corregíamos las redacciones de las compañeras con mucho empeño y señalábamos todos los fallos que encontrábamos, creo que nadie se sintió molesta en ningún momento" (A.10).

- "El ejercicio de analizar los retratos me ha gustado mucho. Ha servido para que aprendamos a apreciar las diferencias existentes en el grupo y también para aceptarlas" (A.4).

- "Me sorprendió descubrir lo que mis compañeras pensaban de mí cuando analizaron mi retrato. Me conocen más de lo que yo creía" (A.12).

- "He disfrutado mucho con esta asignatura porque nos ha enseñado a escribir y a convivir" (A.9).

En síntesis, los resultados obtenidos tras la aplicación de la secuencia didáctica de escritura fueron positivos y contribuyeron a alcanzar los dos objetivos establecidos inicialmente: la mejora progresiva de la redacción y el fomento de la cohesión grupal. Por este motivo, se ha creído conveniente proceder a la difusión de la experiencia con el fin de que pueda ser reproducida en otros escenarios formativos.

\section{Discusión}

En el ámbito de las Ciencias de la Educación pocas actividades y estrategias pedagógicas son replicables de manera exacta y automática, al margen de las características peculiares que conforman cada uno de los contextos de enseñanza, Así pues, es preciso asumir que las acciones descritas en estas páginas están sujetas a un amplio margen de contingencia y que los resultados pueden variar dependiendo de múltiples factores: la predisposición del alumnado, el elevado número de estudiantes por aula, la escasez de tiempo, la reticencia a abordar contenidos que se salgan de la más ortodoxa tradición curricular, etc. En cualquier caso, la pretensión no es ofrecer un recetario o un manual de instrucciones, sino presentar una experiencia singular que puede ser implementada por otros y otras docentes, en la medida de sus posibilidades, o bien servir como referencia o inspiración para el diseño de actividades similares dirigidas a que el estudiantado, además de aprender a escribir mejor, se sienta querido, valorado y respetado en su diversidad. 
Hay palabras y expresiones que, de tanto utilizarlas, derivan en una pérdida progresiva de su significado y terminan por deshumanizarse. "Alumnado" podría ser una de ellas. En el ámbito de la formación -independientemente del nivel educativo - se utiliza tanto y de manera tan general que da la sensación de que las particularidades no existen. El término hace las veces de un enorme paraguas que homogeneiza las características individuales de los sujetos y las reduce a la simple condición de estudiante. Sin embargo, es un hecho que detrás de cada alumno y de cada alumna se esconden multitud de emociones, sentimientos, ilusiones, miedos, anhelos, recuerdos..., que suelen pasar desapercibidos en clase porque las actividades planteadas no son las idóneas para que afloren. Así pues, quizás resulte necesario que, como profesionales de la educación, dediquemos nuestro esfuerzo y nuestra creatividad a diseñar experiencias que permitan acercarnos a cada una de las personas con las que vamos a compartir tiempos, espacios y aprendizajes, aunque eso signifique una disminución en el tiempo destinado a la transmisión de contenidos teóricos.

\section{Referencias}

Boillos-Pereira, M. M. (2018). La autopercepción de las habilidades escritoras en el inicio de la etapa universitaria. ENSAYOS, Revista de la Facultad de Educación de Albacete, 33(2), 149160. https://doi.org/10.18239/ensayos.v33i2.1842

Casas i Vilalta, M., Bosch, D. y González Monfort, N. (2005). Las competencias comunicativas en la formación democrática de los jóvenes: describir, explicar, justificar, interpretar y argumentar. Enseñanza de las Ciencias Sociales, 4, 39-52. https://raco.cat/index.php/EnsenanzaCS/article/view/126245

Cassany, D. (1995). La cocina de la escritura. Anagrama.

Chois-Lenis, P. M., Casas-Bustillo, A. C., López-Higuera, A., Prado-Mosquera, D. M. y Cajas-Paz, E. Y. (2017). Percepciones sobre la tutoría entre pares en escritura académica. Magis, Revista Internacional de Investigación en Educación, 9(19), 165-184. https://doi.org/10.11144/Javeriana.m9-19.ptpe

Del Río-Fernández, J. L. (Coord.). (2019). Investigar para conocer, innovar para mejorar. La formación de docentes investigadores en Educación Inicial. UNAE/OEI.

Di Stefano, M., Pereira, M. C. y Pipkin, M. (2006). La producción de secuencias didácticas de lectura y escritura para áreas disciplinares diversas. Problemas frecuentes. Signo y Seña, 16, 119-135. https://doi.org/10.34096/sys.n16.5710

Díez-Coronado, M. (2016). Porque a escribir se aprende escribiendo. Una propuesta para el aula de ELE. TEJUELO. Didáctica de la Lengua y la Literatura. Educación, 24, 92-110. https://doi.org/10.17398/1988-8430.24.1.92

Dolz, J., y Schneuwly, B. (2011). Escribir es reescribir. La reescritura en las secuencias didácticas para la expresión escrita. Leer.es. Portal de Recursos Educativos, 1-6. https://leer.es/

Errázuriz-Cruz, M. C. (2020). Teorías implícitas sobre escritura de estudiantes y formadores de pedagogía. Magis, Revista Internacional de Investigación en Educación, 13, 1-26. https://doi.org/10.11144/Javeriana.m13.tiee

Elliott, J. (2009). La investigación-acción en educación (6ạ ed.). Morata.

España Palop, E. (2012). Reflexiones sobre la implementación de una secuencia didáctica. Normas. Revista de Estudios Lingüísticos Hispánicos, 2, 63-75. http://hdl.handle.net/10550/24993 
Flores, G. y Porta, L. (2021). La enseñanza en el ámbito universitario: condiciones de su memorabilidad a partir del enfoque biográfico-narrativo. Saberes y Prácticas. Revista de Filosofía y Educación, 6(1), 1-13. https://doi.org/10.48162/art-3815

Gómez-Pardo, R. (2012). Instrucción y (o) formación en los proyectos de lectura y escritura. Una propuesta para educación superior. Magis, Revista Internacional de Investigación en Educación, 4(9), 711-723. https://doi.org/10.11144/Javeriana.m4-9.iofp

Gutiérrez-Rodríguez, M. J. y Flórez-Romero, R. (2011). Enseñar a escribir en la universidad: saberes y prácticas de docentes y estudiantes universitarios. Magis, Revista Internacional de Investigación en Educación, 4(7), 137-168. https://doi.org/10.11144/Javeriana.m47.eeus

Hidalgo Apunte, M. E. (2021). Reflexiones acerca de la evaluación formativa en el contexto universitario. Revista Internacional de Pedagogía e Innovación Educativa, 1(1), 189-210. https://doi.org/10.51660/ripie.v1i1.32

Hocevar, S. (2007). Enseñar a escribir textos narrativos. Diseño de una secuencia didáctica. Lectura y Vida: Revista Latinoamericana de Lectura, 28(4), 50-59.

Martínez, F. J. y Astudillo, J. C. (2021). Alfabetización académica en pregrado a través de una secuencia didáctica basada en el Esquema Numérico de Contenidos. CPU-E Revista de Investigación Educativa, 32, 8-32. https://doi.org/10.25009/cpue.v0i32.2732

McKernan, J. (1999). Investigación-acción y currículum: métodos y recursos para profesionales reflexivos. Morata.

Molina Galvañ, M. D., Quiles-Fernández, E. y Garzón-Poyatos, A. (2020). Entre la escuela y la universidad: la indagación narrativa como pasaje formativo. Revista Interuniversitaria de Formación del Profesorado, 34(1), 213-226. https://doi.org/10.47553/rifop.v34i1.75726

Monsalve Flórez, J. A. (2021). Potenciar la escritura antes y durante la COVID-19: Contraste entre dos secuencias didácticas. Academia y Virtualidad, 14(1), 87-99. https://doi.org/10.18359/ravi.5265

Montesdeoca-Arteaga, D. V., Palacios-Briones, F. E., Gómez-Parra, M. E. y Espejo-Mohedano, R. (2021). Análisis de las habilidades ortográficas en español del estudiantado universitario en Ecuador. Revista Actualidades Investigativas en Educación, 21(1), 1-21. https://doi.org/10.15517/aie.v21i1.44074

Moreno Serna, L., Galindo, A. y Murillo, A. F. (2021). La argumentación persuasiva en primaria desde la secuencia didáctica con enfoque metacognitivo. Lenguaje, 49(2), 438-483. https://doi.org/10.25100/lenguaje.v49i2.11019.

Murillo Sandoval, J. A. y Martínez Valencia, C. A. (2014). Habilidades de pensamiento social: describir, explicar, interpretar y argumentar en el aula. Itinerario Educativo, 64, 108-125 https://doi.org/10.21500/01212753.1421

Robinson, K. (2009). El elemento. Descubrir tu pasión lo cambia todo. Debolsillo.

Rojas Tapia, A. (2014). Leo, luego escribo. Lectura y redacción I. Unisalle.

Ruiz Flores, M. (2009). Evaluación de lengua escrita y dependencia de lo literal. Graó.

Santolària Òrrios, A. (2019). La secuencia didáctica: un instrumento para escribir textos en Educación Infantil. Didáctica. Lengua y Literatura, 31, 285-301. https://doi.org/10.5209/dida.65953 
Tapia-Ladino, M., Correa, R., Ortiz, M. y Neira, A. (2012). Secuencia didáctica para escritura en colaboración en un entorno wiki: Propuesta para estudiantes de Enseñanza Secundaria. Revista Española de Pedagogía, 70(253), 553-571.

Teberosky, A. (2007). El texto académico. En M. Castelló (Coord.). Escribir y comunicarse en contextos científicos y académicos (pp. 17-46). Graó.

Tobón Tobón, S., Pimienta Prieto, J. H. y García Fraile, J. A. (2010). Secuencias didácticas: aprendizaje y evaluación de competencias. Pearson. 